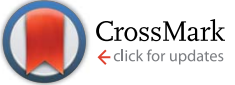

Cite this: RSC Adv., 2017, 7, 6648
Received 25th November 2016 Accepted 28th December 2016 DOI: 10.1039/c6ra27331a

www.rsc.org/advances

\section{All-solid-state asymmetric supercapacitors based on cobalt hexacyanoferrate-derived CoS and activated carbon $\uparrow$}

\begin{abstract}
K. Subramani, ${ }^{a b}$ N. Sudhan, ${ }^{\text {ac }}$ R. Divya ${ }^{a}$ and M. Sathish*a
All-solid-state asymmetric supercapacitors have received significant attention for being flexible, bendable, and wearable energy storage devices due to their optimum energy and power densities. Nanostructured transition-metal chalcogenides have been used as positive electrodes in the asymmetric supercapacitors due to their high theoretical capacitance, good rate capability, and excellent cycling stability. Electrochemically active dumb-bell shaped cobalt sulfide (COS) particles were prepared via solvothermal decomposition of cobalt hexacyanoferrate (COHCF). The dumb-bell shaped particles (2.1 to $2.7 \mu \mathrm{m}$ in length with a lateral size of $\sim 1.3 \mu \mathrm{m}$ ) were formed via the self-assembly of $10-20 \mathrm{~nm}$ sized CoS nanoparticles. CoS exhibited a high specific capacitance of $310 \mathrm{~F} \mathrm{~g}^{-1}$ at a current density of $5 \mathrm{~A} \mathrm{~g}^{-1}$ and 95\% of capacitance retention after 5000 charge-discharge cycles in a three-electrode system. An allsolid-state flexible asymmetric supercapacitor (ASC) device was fabricated using CoS and activated carbon as positive and negative electrodes, respectively. The PVA/KOH-based solid-state electrolyte offers high flexibility to the all-solid-state supercapacitor device. It exhibited a maximum cell voltage of $1.8 \mathrm{~V}$ with a high specific capacitance of $47 \mathrm{~F} \mathrm{~g}^{-1}$ at a current density of $2 \mathrm{~A} \mathrm{~g}^{-1}$. Moreover, the fabricated device delivered a high energy density of $5.3 \mathrm{~W} \mathrm{~h} \mathrm{~kg}^{-1}$ and a high power density of $1800 \mathrm{~W}$ $\mathrm{kg}^{-1}$ with an excellent electrochemical stability of $92 \%$ even after 5000 cycles at $10 \mathrm{~A} \mathrm{~g}^{-1}$ current density. Furthermore, the solvothermal decomposition strategy for the preparation of metal sulfide could be applicable for the preparation of other metal sulfide electrode materials.
\end{abstract}

\section{Introduction}

The development and discovery of new eco-friendly energy generation and storage materials, which must be developed due to the paucity of fossil fuels and their associated health problems in human and the environment, is a must to enervate our energy demands. ${ }^{\mathbf{1}, 2}$ Over the past decade, our inevitable energy needs have been balanced due to energy storage and conversion devices such as batteries and fuel cells., ${ }^{\mathbf{1 , 3} 4}$ In the consideration of energy storage, batteries and conventional capacitors are the

${ }^{a}$ Functional Materials Division, CSIR-Central Electrochemical Research Institute, Karaikudi - 630 003, Tamilnadu, India. E-mail: marappan.sathish@gmail.com; msathish@cecri.res.in

${ }^{b}$ Academy of Scientific and Innovative Research (AcSIR), India

${ }^{c}$ Centre for Education, CSIR-Central Electrochemical Research Institute, Karaikudi 630 003, Tamilnadu, India

$\dagger$ Electronic supplementary information (ESI) available: Comparison table of recent cobalt sulfide based materials, $\mathrm{PVA} / \mathrm{KOH}$ thin film all-solid-state electrolyte, CV and CD profile at different cell voltage, comparison table of electrochemical properties of metal oxide/sulfide based materials, specific capacitance as a function of current density and cell voltage, EIS Nyquist plots of the fabricated flexible all-solid-state ASC, CD profile of the two cells connected in series configuration at different current densities. See DOI: 10.1039/c6ra27331a main devices that persistently store and deliver the power. According to the abovementioned statement, capacitors, as energy storage devices, suffer from low energy density; however, they have high power density. On the other hand, batteries have high energy density and low power density., ${ }^{\mathbf{1 , 2}, \mathbf{4}}$ Due to this inflexible gap between conventional capacitors and batteries, a new advent of electrochemical capacitors is called supercapacitor, which has optimal energy density and power density between conventional capacitors and batteries. ${ }^{\mathbf{1 , 5 , 6}}$ In recent years, significant attention has been paid to supercapacitors research due to their eco-friendliness, energy efficiency, moderate energy density, and high power density. Nowadays, supercapacitors have been employed in portable electronics and hybrid vehicles due to their ingenious properties such as high energy density, fast charge-discharge processes, good cycle life, and low maintenance cost. ${ }^{3,4}$ Based on the materials and the charge storage mechanism, supercapacitors can be categorized into two types. One is electric double-layer capacitors (EDLCs) type of materials that can store energy by physical adsorption and desorption processes that occur at the electrode and electrolyte interface. ${ }^{\mathbf{1 , 6}, 7}$ The other type is pseudocapacitive materials, which has gained extensive interest due to their fast surface redox reactions and high specific capacitance. ${ }^{7}$ However, pseudocapacitive materials also suffer from some 
disadvantages related to the limitation of energy and power densities. Recently, hybrid-based asymmetric supercapacitors (ASC) have received significant attention due to their improved energy density with maximum power. Generally, ASC consists of faradaic and non-faradaic components such as metal oxide (or metal sulfide) electrode materials and carbonaceous electrode materials, respectively. In fact, the faradaic component is responsible for the energy and the non-faradaic component influences the power. ${ }^{8-11}$ Accordingly, a combination of both components can improve the overall enhanced cell voltage. To the best of our knowledge, other commercially offered supercapacitors in the market do not have this kind of asymmetric configuration.

In recent years, metal oxide/sulfide-based electrode materials are more interesting towards supercapacitor applications due to their high specific capacitance, excellent redox reversibility, and high electrical conductivity. ${ }^{\mathbf{1 2 - 1 5}}$ In recent times, a raft of sulfidebased electrode materials, such as $\mathrm{CoS}$, NiS, $\mathrm{Ni}_{3} \mathrm{~S}_{2}, \mathrm{SnS}_{2}, \mathrm{CuS}$, $\mathrm{MnS}, \mathrm{NiCo}_{2} \mathrm{~S}_{4}$, and $\mathrm{Co}_{3} \mathrm{~S}_{4}$, have been employed as emerging type of electrode materials for supercapacitors. ${ }^{16-21}$ Typically, different types of nanostructures can be responsible for effective energy storage and improve the electrochemical performance of electrode materials. ${ }^{\mathbf{8}, 9}$ More specifically, morphologies can be tuned by employing various synthesis methods such as hydrothermal, solvothermal, and supercritical fluid syntheses ${ }^{22}$ (Table S1 $\dagger$ ). Recently, a few sulfide-based electrode materials, such as nanowires, ${ }^{23}$ nano-tubes, ${ }^{24}$ nano-sheets, ${ }^{25}$ nano-strip-like, ${ }^{26}$ and nanoflower-like $^{27}$ structures, with some remarkable morphologies have been reported. The morphology of the electrode materials also has a higher impact on the overall performance of the supercapacitor device. To achieve a wide potential window, organic electrolytes or ionic liquid-based electrolytes have been used in supercapacitor applications..$^{28-30}$ However, the use of abovementioned non-aqueous electrolytes has been restricted due to their toxicity, limited ionic conductivity, and poor costeffectiveness. Herein, to stabilize these effects, an aqueous asymmetric supercapacitor (ASC) with a maximum cell voltage of $1.8 \mathrm{~V}$ has been introduced. ${ }^{31,32}$

Solid-state gel electrolytes have been used in supercapacitor devices to attain flexible, bendable, and paper-like modulations for miniaturizing the current devices. ${ }^{\mathbf{1 0}, 33}$ Recently, X. Meng et $a{ }^{16}{ }^{16}$ reported the hydrothermal synthesis of interconnected three-dimensional (3D) structured CoS/graphene composite hydrogel (3D CGH) materials. Compared to that of pure CoS (433 $\mathrm{F} \mathrm{g}^{-1}$ ), 3D CGH exhibits a high specific capacitance of $564 \mathrm{~F} \mathrm{~g}^{-1}$ at a current density of $1 \mathrm{~A} \mathrm{~g}^{-1}$. R. B. Rakhi et al. ${ }^{34}$ have reported that porous cobalt sulfide $\left(\mathrm{Co}_{9} \mathrm{~S}_{8}\right)$ nanostructures, which directly develops over the carbon fiber, can be used as electrodes for asymmetric hybrid supercapacitors. In this study, asymmetric hybrid supercapacitors were constructed from $\mathrm{Co}_{9} \mathrm{~S}_{8}$ and activated carbon (AC) as cathode and anode, respectively, with a cell voltage of $1.6 \mathrm{~V}$. The $2 \mathrm{D} \mathrm{Co}_{9} \mathrm{~S}_{8} \|$ AC asymmetric hybrid supercapacitor exhibits a gravimetric cell capacitance of $82.9 \mathrm{~F} \mathrm{~g}^{-1}$ at a constant current density of $1 \mathrm{~A} \mathrm{~g}^{-1}$. S. Liu et al..$^{35}$ have reported ultra-long cobalt sulfide $\left(\mathrm{CoS}_{1.097}\right)$ nanotube networks, synthesized by a simple one-step solvothermal method, in the working potential range from 0 to $1.5 \mathrm{~V}$ with a calculated specific capacitance of $107 \mathrm{~F} \mathrm{~g}^{-1}$ at $1 \mathrm{~A} \mathrm{~g}^{-1}$. The capacitance retention was 91.7\% and 83.3\%, even after 2000 cycles and 5000 cycles, respectively. J. Shi et al. ${ }^{36}$ demonstrated the fabrication of a highperformance 3D CoS/graphene hybrid network on a $\mathrm{Ni}$ foam surface via a two-step electrodeposition process. The fabricated CoS/graphene||AC asymmetric supercapacitor in a $2 \mathrm{M} \mathrm{KOH}$ solution exhibited a maximum specific capacitance of $80 \mathrm{~F} \mathrm{~g}^{-1}$ at a current density of $1 \mathrm{~A} \mathrm{~g}^{-1}$. From the abovementioned studies, it is obvious that CoS-based electrode materials exhibit good electrochemical behavior for full cell studies. To our knowledge, there are only few limited reports available for the CoS-based flexible and bendable all-solid-state asymmetric supercapacitors.

Herein, we demonstrated the preparation of CoS nanoparticles via simple solvothermal decomposition of cobalt hexacyanoferrate (CoHCF). The prepared materials were characterized by XRD, FTIR spectroscopy, FE-SEM analysis, and HR-TEM analysis. The electrochemical properties of CoS and activated carbon (AC) were investigated by cyclic voltammetry (CV) and galvanostatic charge/ discharge (CD) experiments. All-solid-state flexible asymmetric supercapacitor (ASC) cells were fabricated using PVA $/ \mathrm{KOH}, \mathrm{CoS}$, and $\mathrm{AC}$ as a polymer solid-state gel electrolyte, cathode and anode materials, respectively. The flexible ASC cell exhibited a high energy and power density of $5.3 \mathrm{~W} \mathrm{~h} \mathrm{~kg}^{-1}$ and $9000 \mathrm{~W} \mathrm{~kg}^{-1}$, respectively, with an excellent electrochemical stability of $92 \%$, even after 5000 cycles at a high current density. Note that this methodology is readily applicable for preparing other metal sulfide nanoparticles for electrochemical applications.

\section{Materials and methods}

\subsection{Materials}

Cobalt nitrate $\left[\mathrm{Co}\left(\mathrm{NO}_{3}\right)_{2} \cdot 6 \mathrm{H}_{2} \mathrm{O}, 99 \%\right]$, activated carbon (mesoporous graphitized carbon black, 99.95\%), poly(vinyl alcohol) $\left(\left[-\mathrm{CH}_{2} \mathrm{CHOH}-\right]_{n}, M_{\mathrm{w}} \sim 125000\right)$, and PVDF poly(vinylidene fluoride) were purchased from Sigma-Aldrich, India. Sodium sulfide $\left(\mathrm{Na}_{2} \mathrm{~S}\right)$, potassium hydroxide $(\mathrm{KOH})$, sodium hydroxide $(\mathrm{NaOH})$, ethanol $\left(\mathrm{CH}_{3} \mathrm{CH}_{2} \mathrm{OH}\right), \mathrm{N}$-methyl-2-pyrrolidone (NMP), L-ascorbic acid, and potassium ferricyanide $\left(\mathrm{K}_{3}\left[\mathrm{Fe}(\mathrm{CN})_{6}\right], 99 \%\right)$ were purchased from E-Merck Co. Ltd. Graphite foil $(0.13 \mathrm{~mm}$ thick, 99.8\%) was purchased from Alfa Aesar India Pvt. Ltd. All purchased chemicals were of analytical grade and used as received without any further purification. Deionized (DI) water was obtained through a Millipore water system.

\subsection{Preparation of the CoHCF complex and CoS nanoparticles}

The two-step synthesis of CoS nanoparticles was carried out through the formation of a CoHCF complex followed by solvothermal conversion into crystalline $\mathrm{CoS}$ nanoparticles. In a typical preparation, $10 \mathrm{mM} \mathrm{Co}\left(\mathrm{NO}_{3}\right)_{2} \cdot 6 \mathrm{H}_{2} \mathrm{O}$ was slowly added to $10 \mathrm{mM}$ of $\mathrm{K}_{3}\left[\mathrm{Fe}(\mathrm{CN})_{6}\right]$ and stirred for $3 \mathrm{~h}$. The resulting CoHCF complex was washed with DI water and dried at $70^{\circ} \mathrm{C}$ in a hot air oven. Then, $300 \mathrm{mg}$ of dried CoHCF powder (dissolved in $10 \mathrm{ml}$ ethanol) was mixed with $100 \mathrm{mg}$ of ascorbic acid (dissolved in $10 \mathrm{ml}$ ethanol). To this mixture, $2.4 \mathrm{~g}$ of sodium sulfide (dissolved in $10 \mathrm{ml}$ of ethanol) was added and stirred for 
$1 \mathrm{~h}$. The resulting mixture $(30 \mathrm{ml})$ was transferred to a $50 \mathrm{ml}$ Teflon-lined stainless steel autoclave and kept in a hot air oven at $180{ }^{\circ} \mathrm{C}$ for $24 \mathrm{~h}$. The resulting precipitate was filtered, washed with DI water followed by ethanol, and finally dried at $70{ }^{\circ} \mathrm{C}$ for $3 \mathrm{~h}$. The dried cake was ground to make a fine CoS powder.

\subsection{Materials characterization}

The phase formation and crystalline nature of the CoS nanoparticles was examined by powder X-ray diffraction (XRD) (Bruker D8 Advance X-ray diffractometer) using $\mathrm{Cu} \mathrm{K}_{\alpha}$ radiation $(\lambda=$ $1.5418 \AA$ ) in the $2 \theta$ range from 10 to $80^{\circ}$ at $0.02^{\circ}$ steps with a count time of $0.2 \mathrm{~s}$ at each step. Fourier transform infrared (FTIR) spectra were obtained by a Tensor 27 spectrometer (Bruker) from 400 to $4000 \mathrm{~cm}^{-1}$ using the $\mathrm{KBr}$ pellet technique. Nitrogen adsorption-desorption isotherm and pore-size distribution of the CoS nanoparticles was measured using a Quantachrome NOVA 3200e surface area analyzer. The morphology and particle size of the CoS nanoparticles were analyzed by field-emission scanning electron microscopy (FE-SEM, Carl Zeiss Supra 55VP) and high resolution-transmission electron microscopy (HR-TEM, Tecnai G2 TF20).

\subsection{Electrochemical characterization}

The electrochemical behavior of CoS nanoparticles was studied via $\mathrm{CV}, \mathrm{CD}$, and electrochemical impedance spectroscopy (EIS) using a potentiostat-galvanostat (SP-300, BioLogic) instrument. The working electrode was prepared by mixing CoS nanoparticles, activated carbon, and PVDF at a $75: 20: 5$ weight ratio in $N$-methyl-2-pyrrolidone (NMP) as a solvent, respectively. The resulting slurry was coated over a graphite foil $(2 \times 2 \mathrm{~cm})$ current collector and dried in a vacuum oven at $70{ }^{\circ} \mathrm{C}$ for $5 \mathrm{~h}$. The active materials loading ( $\sim 2 \mathrm{mg}$ ) was calculated using the weight difference of the graphite foil before and after coating. The AC negative electrode was prepared by mixing $95 \%$ of AC and $5 \%$ PVDF in NMP, and the resulting slurry was coated on a graphite foil $(2 \times 2 \mathrm{~cm})$ current collector and dried in a vacuum oven at $70{ }^{\circ} \mathrm{C}$ for $5 \mathrm{~h}$. For the three-electrode configuration, electrode materials coated graphite foils, $\mathrm{Hg} / \mathrm{HgO}(20 \% \mathrm{KOH})$, and a slice of Pt foil were used as a working electrode, reference electrode, and counter electrode, respectively. CV, CD, and EIS measurements were carried out using $3.5 \mathrm{M} \mathrm{KOH}$ electrolyte at different scan rates ( 5 to $50 \mathrm{mV} \mathrm{s}^{-1}$ ) and various current densities ( 5 to $50 \mathrm{~A}$ $\left.\mathrm{g}^{-1}\right)$. The specific capacitance values of $\mathrm{CoS}$ and AC were estimated from the discharge profile using the following equation:

$$
C_{\mathrm{sp}}=\frac{I \Delta t}{m \Delta V}
$$

where $C_{\mathrm{sp}}\left(\mathrm{F} \mathrm{g}^{-1}\right)$ is the specific capacitance of the electrode material, $I(\mathrm{~A})$ is the current, $\Delta t(\mathrm{~s})$ is the discharge time, $m(\mathrm{~g})$ is the active mass of the electrode, and $\Delta V(\mathrm{~V})$ is the working potential window. The supercapacitor performance of CoS was studied by fabricating an asymmetric supercapacitor device using $\mathrm{CoS}$ as the positive electrode and $\mathrm{AC}$ as the negative electrode in a PVA/KOH-based all-solid-state electrolyte. The specific capacitance, energy density and power density were calculated using the following equations: $\mathbf{1}^{\mathbf{1 1 0}}$

$$
\begin{gathered}
C_{\mathrm{t}}=\frac{I \Delta t}{m \Delta V} \\
C_{\mathrm{sp}}=4 C_{\mathrm{t}} \\
E=\frac{1}{2} C_{\mathrm{t}} \Delta V^{2} \\
P=\frac{E}{\Delta t}
\end{gathered}
$$

where $C_{\mathrm{t}}\left(\mathrm{F} \mathrm{g}^{-1}\right)$ is total capacitance, $C_{\mathrm{sp}}$ is the specific capacitance of the electrode materials $\left(\mathrm{F} \mathrm{g}^{-1}\right), I$ is the current (A), $\Delta t$ is the discharge time (sec), $m$ is the total mass of the electrodes in both electrodes $(\mathrm{g})$ and $\Delta V$ is working potential window $(\mathrm{V})$. EIS experiments were performed from $10 \mathrm{mHz}$ to $10 \mathrm{kHz}$ with a $5 \mathrm{mV}$ bias voltage.

\subsection{Preparation of the PVA/KOH all-solid-state gel electrolyte}

The alkaline $\mathrm{PVA} / \mathrm{KOH}$ polymer electrolyte was prepared by a solution-casting method similar to that reported in the literature..$^{37,38}$ Initially, $1.0 \mathrm{~g}$ of PVA was dissolved in $25 \mathrm{ml}$ of water with continuous stirring for about $4 \mathrm{~h}$ at $80{ }^{\circ} \mathrm{C}$. After complete dissolution of the PVA polymer, $1.0 \mathrm{~g}$ of $\mathrm{KOH}$ (dissolved in $25 \mathrm{ml}$ water by continuous stirring for $5 \mathrm{~h}$ at $95^{\circ} \mathrm{C}$ ) was added and the resulting solution was continuously stirred until the formation of a homogeneous viscous solution. The abovementioned viscous solution was poured into Petri dishes and allowed to slowly dry at room temperature to form a thin film, and the average thickness of the thin film was $\sim 0.3 \mathrm{~mm}$ (Fig. S1 $\dagger$ ).

\section{Results and discussion}

Decomposition of the CoHCF complex by an alkali results in the formation of $\mathrm{Co}(\mathrm{OH})_{2}$ precipitate that gets oxidized further to $\mathrm{Co}_{3} \mathrm{O}_{4}$ without any heat treatment. ${ }^{39}$ Herein, the CoHCF complex was solvothermally $\left(180{ }^{\circ} \mathrm{C}\right.$ for $\left.24 \mathrm{~h}\right)$ converted into cobalt sulfide in presence of $\mathrm{Na}_{2} \mathrm{~S}$ and ascorbic acid as the sulfide source and mild reducing agent, respectively. Fig. 1 represents the schematic of the CoS nanoparticles preparation by solvothermal decomposition of CoHCF in the presence of ascorbic acid and a sulfide source. Note that ultra-fine crystalline CoS nanoparticles were formed without any high temperature calcination process.

Powder X-ray diffraction pattern (PXRD) is a primary analytical tool to identify the crystalline nature of the materials. Fig. 2a shows the XRD patterns of the CoHCF complex, CoS nanoparticles and their respective ICDD reference patterns. All the diffraction peaks of the CoHCF complex were indexed with the standard cubic CoHCF phase, which is in good agreement with the ICDD card number 01-075-0038. The observed diffraction peaks at $17.9,25.4,36.2,40.5,44.7,52.2$, and $58.9^{\circ}$ were assigned to the (200), (220), (400), (200), (422), (440), and (620) reflection lines of the CoHCF complex, respectively. Moreover, the highly intense reflection line indicates the good crystallinity of the synthesized CoHCF complex. The average crystalline size of the particles was calculated from the XRD pattern using the Debye-Scherrer ${ }^{40}$ equation as follows: 


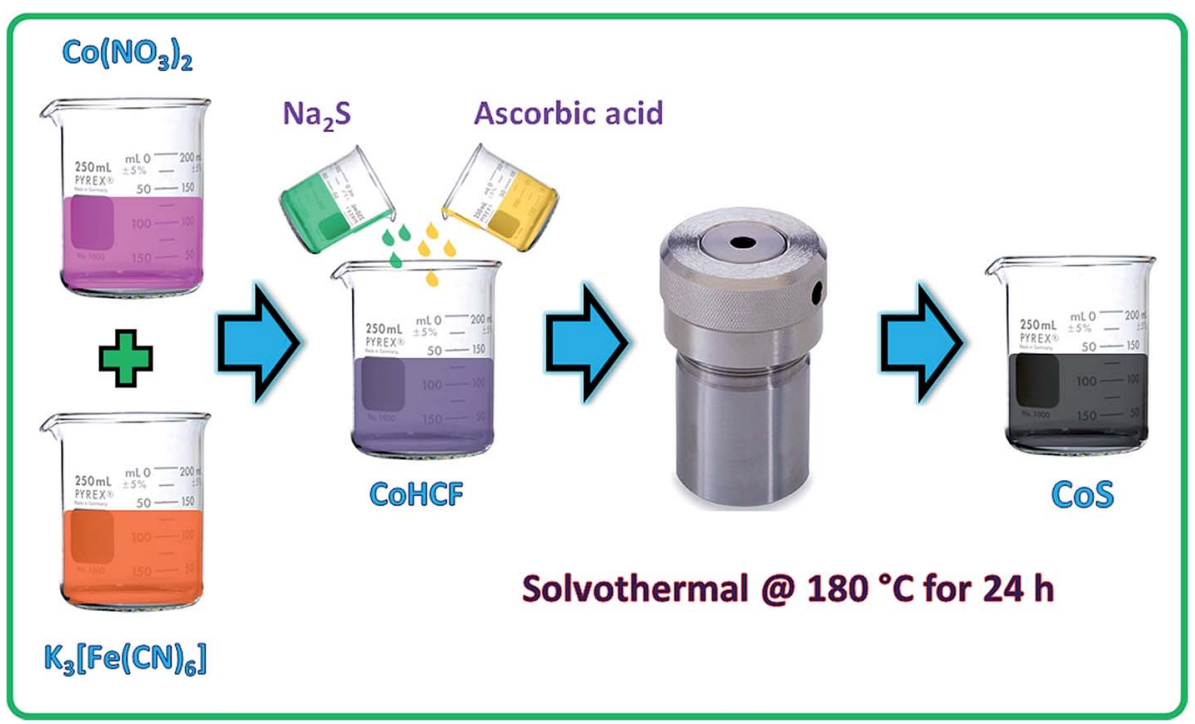

Fig. 1 Schematic of the CoHCF complex preparation and solvothermal decomposition of CoHCF into CoS nanoparticles.

$$
D=\frac{k \lambda}{\beta \cos \theta}
$$

where $D$ is the average crystallite size, $\lambda$ is the $\mathrm{X}$-ray wavelength $\left(\mathrm{Cu}, \mathrm{K}_{\alpha 1}\right), \beta$ is the full width at half maximum and $\theta$ is the angle of diffraction. The calculated average crystalline size of CoHCF was $\sim 17 \mathrm{~nm}$. After the solvothermal treatment, the observed reflection lines for the obtained product were matched with the hexagonal phase of CoS with ICDD card number 03-065-3418. The observed diffraction lines at 30.7, 35.3, 46.9, 54.3, and 75.5 were assigned to the (100), (101), (102), (110), and (202) reflection lines of the hexagonal CoS, respectively. The calculated average crystallite size of CoS was $\sim 8 \mathrm{~nm}$. This clearly demonstrated that the solvothermal decomposition of the CoHCF complex in the presence of a sulfur source and ascorbic acid (mild reducing agent) results in the formation of hexagonal CoS nanoparticles. In addition, the very weak diffraction lines at 20.2, 22.0, and $24.8^{\circ}$ indicate (shown as \# in Fig. 2a) the formation of elemental sulfur impurities in the sample.

The presence of various functional groups in the synthesized materials was examined using FT-IR spectroscopy between 4000 to $400 \mathrm{~cm}^{-1}$ and the results are shown in Fig. $2 \mathrm{~b}$. The two broad $\nu_{\mathrm{CN}}$ absorption bands of PB-structured materials (between 2000 and $2200 \mathrm{~cm}^{-1}$ ) is the diagnostic of the C-bound metal ion and its oxidation state. ${ }^{41}$ In this region, the CoHCF showed two peaks: one strong peak at $2162 \mathrm{~cm}^{-1}$ and a weak peak at 2099 $\mathrm{cm}^{-1}$. The absorption band at $2099 \mathrm{~cm}^{-1}$ might be attributed to the $\mathrm{CN}$ stretching in the cobalt-iron cyanide $\left(\mathrm{Fe}^{2+}-\mathrm{CN}-\mathrm{Co}^{3+}\right)$ of $\mathrm{PB}$ analogue CoHCF. ${ }^{42}$ The vibration peaks corresponding to $\mathrm{OH}$ bonding on the surface of CoS nanoparticles have been observed around $3430 \mathrm{~cm}^{-1}$ and reveals that the as-synthesized samples were highly hydrous in nature. The peaks at 1620 and $1100 \mathrm{~cm}^{-1}$ for $\mathrm{CoS}$ were due to the bending vibration of adsorbed $\mathrm{H}_{2} \mathrm{O}$ molecules and sulphonated groups in the pure CoS nanoparticles. The presence of the sulfur linkage was confirmed by the presence of a peak observed at $605 \mathrm{~cm}^{-1}$. The surface area and porous nature of the electrode materials are key parameters for determining the electrochemical performance. Fig. S2 $\uparrow$ reveals the Brunauer-Emmett-Teller (BET) $\mathrm{N}_{2}$ adsorption/desorption isotherms with a distinct hysteresis loop in the range from 0.45 to $1.0\left(P / P_{0}\right)$ that suggest a typical type-IV isotherm (for a mesoporous nature). The BET surface area of 28 $\mathrm{m}^{2} \mathrm{~g}^{-1}$ was obtained for the CoS nanoparticles. Based on the adsorption-desorption profile, fitted with the Barrett-JoynerHalenda (BJH) model, a narrow pore size distribution between 6 and $8 \mathrm{~nm}$ with a total pore volume of $0.107 \mathrm{~cm}^{3} \mathrm{~g}^{-1}$ was observed (Fig. $\mathrm{S} 2 \uparrow$ (inset)).

The surface morphology and particle size of the assynthesized CoS nanoparticles were analyzed using FE-SEM and HR-TEM, respectively. The FE-SEM images (Fig. 2c and d) reveal the dumb-bell-like morphology of the CoS nanoparticles at low magnification. It can be clearly seen that the dumb-bellshaped particles are well dispersed in the entire sample. The length of the dumb-bell shaped CoS was in the range from 2.1 to $2.7 \mu \mathrm{m}$ and each side of the dumb-bell had an average lateral size of $\sim 1.3 \mu \mathrm{m}$ (Fig. 2e). The dumb-bell shape of CoS was formed by the assembly of 10-20 nm sized CoS nanoparticles (Fig. 2f). The dumb-bell-like CoS was further studied via HRTEM analysis at different magnifications, as shown in Fig. 3. Fig. $3 \mathrm{a}$ and $\mathrm{b}$ clearly confirms the homogeneous dispersion of ultra-fine CoS nanoparticles on the dumb-bell-like assembly. Fig. $3 \mathrm{c}$ and $\mathrm{d}$ reveals the formation of ultra-fine CoS nanoparticles in the range of $\mathbf{5 - 1 0 ~} \mathrm{nm}$ in size. The calculated particles sizes were in good correspondence with the XRD observations. The observed lattice fringes, with $d$-spacings of 0.250 and $0.191 \mathrm{~nm}$ corresponding to (101) and (102) planes, respectively, confirmed the formation of crystalline spinal-type cubic CoS nanoparticles, as shown in Fig. 3d. The observed FFT pattern (Fig. 3d inset) confirms the existence of the polycrystalline nature of the CoS nanoparticles. From the abovementioned electron microscopic analysis, it is clear that ultrafine crystalline CoS nanoparticles of 5-10 $\mathrm{nm}$ in size were 

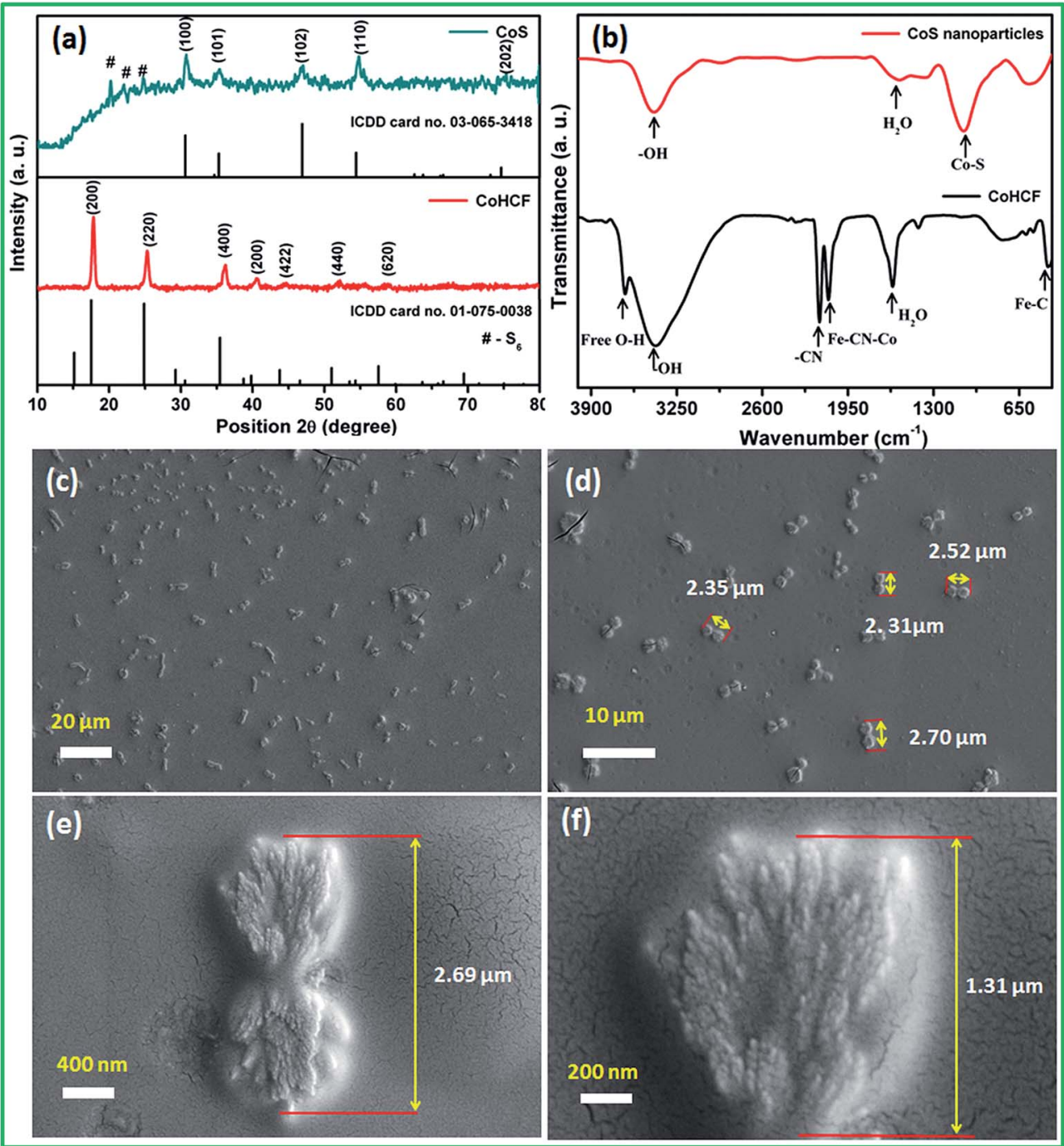

Fig. 2 (a) XRD pattern, (b) FT-IR spectra of the CoHCF complex and CoS nanoparticles, and (c-f) FE-SEM images of the as-synthesized CoS at different magnifications.

formed during the solvothermal decomposition of the CoHCF complex in the presence of ascorbic acid and sodium sulfide. Moreover, the resulting $\operatorname{CoS}$ nanoparticles self-assembled into an overall dumb-bell-like shapes.

\subsection{Electrochemical characterization}

3.1.1. Positive electrode materials. Cyclic voltammetry (CV), galvanostatic charge/discharge (CD), and electrochemical impedance spectroscopy analyses are the characterization tools for evaluating the electrochemical performance of the electrode materials. The CoS electrode material was evaluated using $\mathrm{CV}$ from 0 to $0.6 \mathrm{~V}$ ( $v s$. $\mathrm{Hg} / \mathrm{HgO}$ ) at various scan rates in a $3.5 \mathrm{M}$ $\mathrm{KOH}$. The typical CV profile of the CoS electrodes at different scan rates, such as $5,10,20,30,40$, and $50 \mathrm{mV} \mathrm{s}^{-1}$, is shown in Fig. 4a. The CV curves are non-symmetrical with two sets of redox peaks, and this clearly confirms the existence of a pseudocapacitive nature. The oxidation and reduction peaks in the anodic and cathodic regions were attributed to the reversible faradaic process between $\mathrm{Co}^{2+} / \mathrm{Co}^{3+}$ and $\mathrm{Co}^{3+} / \mathrm{Co}^{4+}$ in the presence of alkaline $\mathrm{OH}^{-}$anions, respectively. According to the literature, the possible redox reactions can be described as follows: ${ }^{16,25,34}$

$$
\begin{gathered}
\mathrm{CoS}+\mathrm{OH}^{-} \rightleftharpoons \mathrm{CoSOH}+\mathrm{e}^{-} \\
\mathrm{CoSOH}+\mathrm{OH}^{-} \rightleftharpoons \mathrm{CoSO}+\mathrm{H}_{2} \mathrm{O}+\mathrm{e}^{-}
\end{gathered}
$$

The linear relationship observed between the redox peak current and the square root of the scan rate (Randles-Sevcik ${ }^{\mathbf{4}}$ plot) suggests that the electrode surface reactions at all scan rates were diffusion-controlled processes (Fig. 4b). The observed redox peaks involved $\mathrm{OH}^{-}$diffusion from the electrolyte to the electrode surface and from the electrode to the electrolyte during the reduction and oxidation processes, respectively.

The specific capacitances of the electrode materials were calculated using CD experiments from 0 to $0.5 \mathrm{~V}$ (vs. $\mathrm{Hg} / \mathrm{HgO}$ ) potential range at various current densities (Fig. 4c). The 


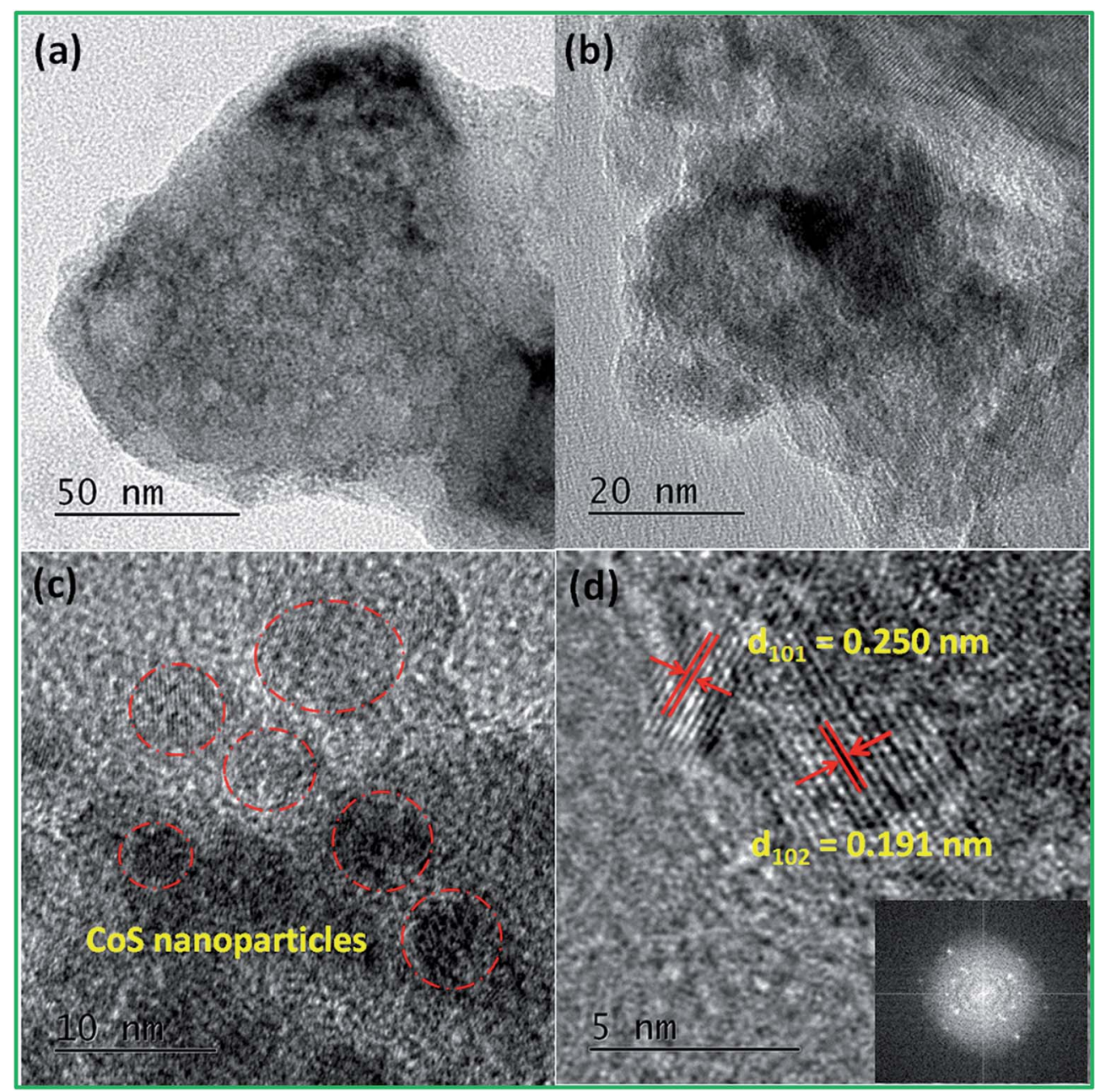

Fig. 3 (a-d) High resolution transmission electron microscopy images of the CoS nanoparticles at different magnifications and the FFT image (inset).

humps observed in the CD profiles at all current densities confirmed the pseudocapacitive behavior of the electrode materials, which were in good agreement with the CV studies. From the CD curve, very high specific capacitances of 310, 290, 232, and $184 \mathrm{~F} \mathrm{~g}^{-1}$ were obtained at 5, 10, 30, and $50 \mathrm{~A} \mathrm{~g}^{-1}$ current densities, respectively. The specific capacitance as a function of current density is shown in Fig. $4 d$, and it is clear from the plot that even at a high current density of $50 \mathrm{~A} \mathrm{~g}^{-1}$, the CoS electrode retains $60 \%$ of the initial capacitance. The observed excellent rate performance of $\operatorname{CoS}$ nanoparticles clearly confirms that they are the best materials for high power density applications. The long-term stability of the CoS nanoparticles electrode was studied using 5000 charge/discharge cycles at $50 \mathrm{~A} \mathrm{~g}^{-1}$ (Fig. 4e). 95\% of the initial capacitance was retained after 5000 charge/discharge cycles with $99.5 \%$ coulombic efficiency, which is one of the best values among those reported in literature to date.

To understand the charge transfer process in the CoS nanoparticles electrode/electrolyte interface and the resistance, EIS was performed in the frequency range from $10 \mathrm{mHz}$ to 100 $\mathrm{kHz}$, with an alternating current amplitude of $5 \mathrm{mV}$, and the resulting Nyquist plot is shown in Fig. 4f. The EIS curves of the electrode materials show the presence of solution resistance or bulk resistance $\left(R_{\mathrm{S}}\right)$, semicircle at a high frequency region, and linear line greater than $45^{\circ}$ to the real axis towards the imaginary axis at low frequency regions, which suggests the good capacitive behavior of the material. All the EIS curves were fitted with an equivalent circuit containing various $R$ and $C$ components (Fig. $4 \mathrm{f}$ inset). The CoS electrode material showed an $R_{\mathrm{s}}$ value of $\sim 0.31 \Omega$, which clearly indicates that the ionic resistance of the electrolyte was less and helped for better electron transport during charge/discharge cycling. The semicircle at the high frequency region corresponds to the combination of charge-transfer resistance $\left(R_{\mathrm{ct}} \sim 0.85 \Omega\right)$ and double layer capacitance $\left(C_{\mathrm{dl}}\right)$ at the electrode/electrolyte interface. ${ }^{39}$ The intercepts of the semicircle with the real axis at $R_{\mathrm{s}}$ and $\left(R_{\mathrm{s}}+R_{\mathrm{ct}}\right)$ provides the $R_{\mathrm{ct}}$ and $R_{\mathrm{s}}$ values, respectively. The straight line in the high frequency region was more vertical and had less imaginary parts, corresponding to the low diffusion resistance (Warburg impedance, $W$ ) ${ }^{36} C_{\mathrm{F}}$ denotes the pseudocapacitance component of the electrode materials, which was due to the electrochemical faradaic transition of $\mathrm{CoS}$ in an alkali medium. 


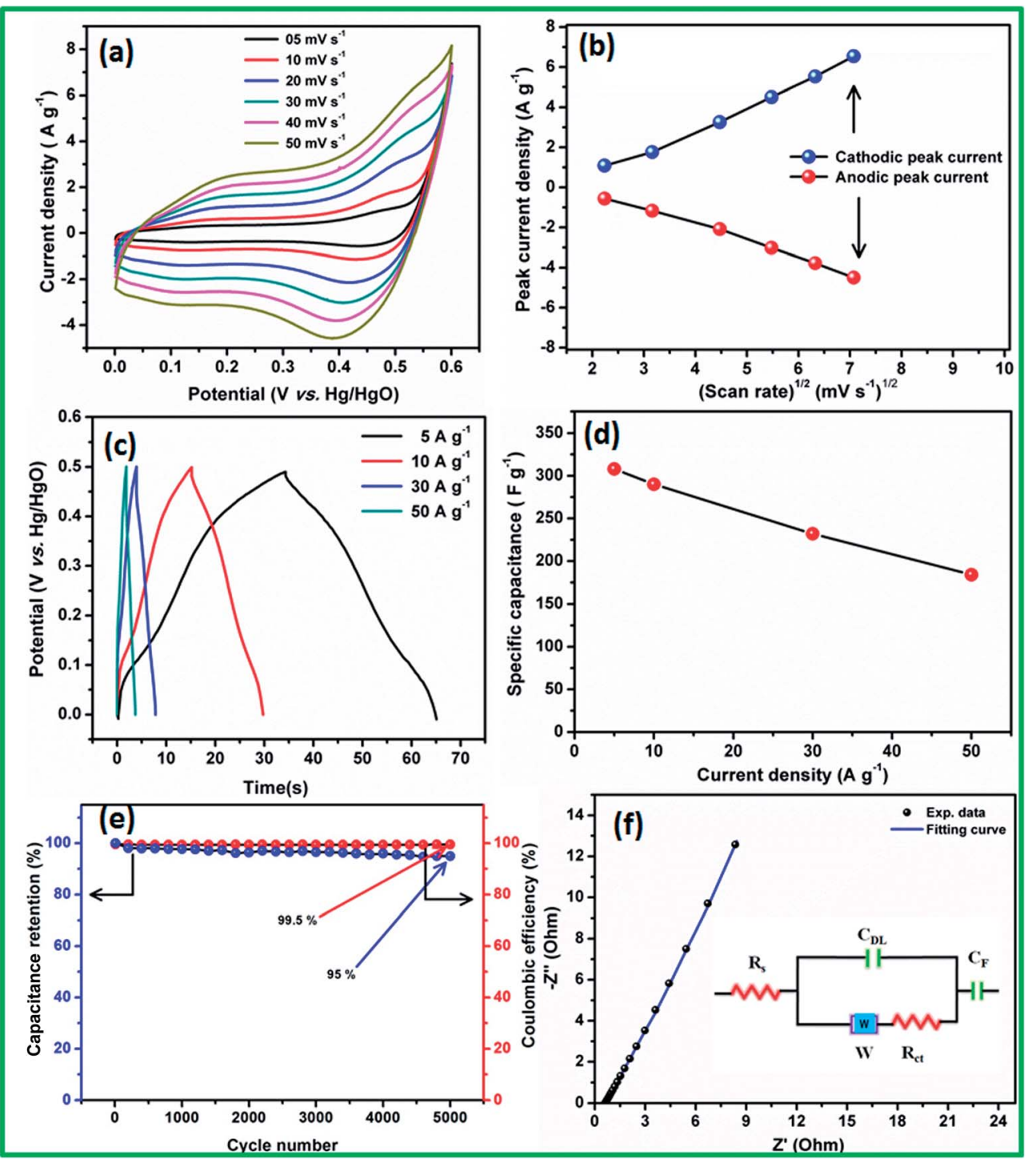

Fig. 4 (a) CV profile of the CoS electrode at different scan rates. (b) Peak current density as a function of scan rate. (c) CD profile of the CoS electrode at different current densities. (d) Specific capacitance of the CoS electrode as a function of current density. (e) Specific capacitance retention of the CoS electrode as a function of cycle number at $50 \mathrm{~A} \mathrm{~g}^{-1}$. (f) EIS analysis of the CoS electrode and corresponding equivalent circuit (inset) in a $20 \% \mathrm{KOH}$ solution.

3.1.2. Negative electrode materials. To fabricate the full cell asymmetric supercapacitor, it is a prerequisite to study the cathode and anode-based electrode materials under similar electrochemical conditions, such as in the same alkali electrolyte, scan rate, and current densities. Generally, carbon-based electrode materials are extensively used as negative electrode materials for asymmetric supercapacitors. ${ }^{\mathbf{4 4 , 4 5}}$ In this study, commercially available activated carbon (AC), obtained from Sigma-Aldrich, was used as a negative electrode. To evaluate the electrochemical performance of AC in a 3.5 M KOH electrolyte, $\mathrm{CV}$ and $\mathrm{CD}$ analyses were carried out in the potential range from -1 to $0 \mathrm{~V}$ (vs. $\mathrm{Hg} / \mathrm{HgO})$ at various scan rates and current densities, respectively. The CV curves shown in Fig. 5a indicate the mirror image characteristics with perfect rectangular shape curves without any redox peaks. This clearly confirms that the capacitance behavior of AC mainly originated from the EDLCs. The galvanostatic charge-discharge profile of AC shows a linear and symmetrical curve at various current densities ranging from 1 to $20 \mathrm{~A} \mathrm{~g}^{-1}$, which clearly confirms the EDLCs behavior of the AC electrode materials (Fig. 5b). In all the discharge curves, only negligible internal resistance (iR) was observed due to the good electrical contact between the electrode materials and the current collector. This high electrical conductivity of the electrode materials facilitates the electron charge transfer reaction at the interface by fast surface adsorption-desorption reactions. The calculated specific capacitances of AC from the discharge curve were $85,70,66,62,60,50$, and $39 \mathrm{~F} \mathrm{~g}^{-1}$ at 1, 2, 3, $4,5,10$, and $20 \mathrm{~A} \mathrm{~g}^{-1}$ current densities, respectively. Fig. 5c reveals the specific capacitance as a function of current density, 

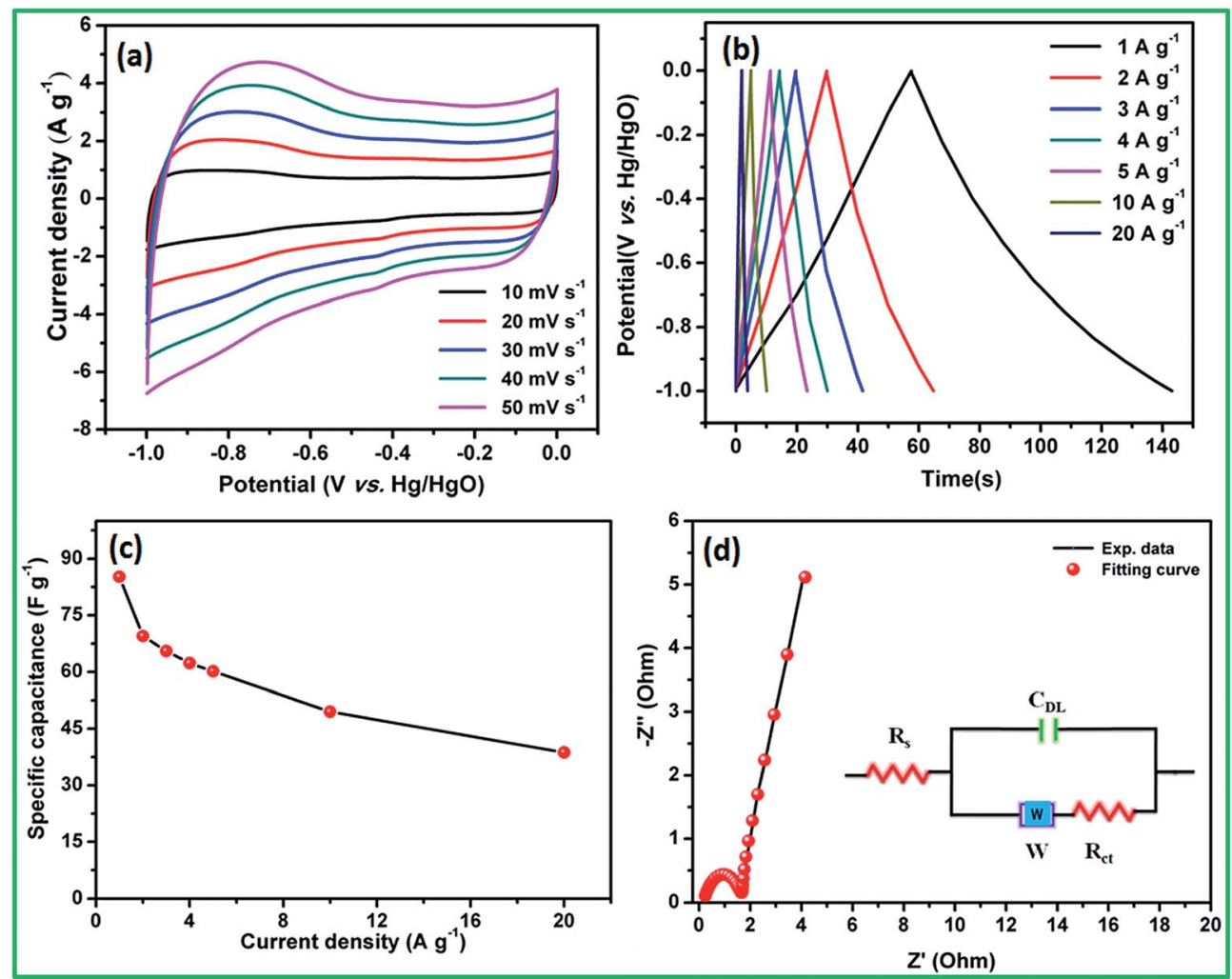

Fig. 5 (a) CV profile of AC at different scan rates. (b) Galvanostatic charge-discharge profile of AC at different current densities. (c) Specific capacitance of the AC electrode as a function of current density. (d) EIS Nyquist plots of the AC electrode materials and its corresponding equivalent circuit (inset) in $20 \% \mathrm{KOH}$ solution.

and it could be clearly seen that even at high current density $(20$ A $\mathrm{g}^{-1}$ ), the materials have excellent rate performance. The typical Nyquist plots of AC electrode materials showed $R_{\mathrm{S}}$ and $R_{\text {ct }}$ values of $\sim 0.24$ and $1.35 \Omega$, respectively, with a double layer capacitance $\left(C_{\mathrm{dl}}\right)$ (Fig. $5 \mathrm{~d}$ ). The straight line at the high frequency region is more vertical and has less imaginary parts, which is close to that of the ideal capacitor. This indicates that the AC facilitated fast electron transfer between the AC and the current collector due to the low-diffusion resistance. This excellent electrochemical feature of AC helps it to act as a good negative electrode material for the fabrication of asymmetric supercapacitors.

3.1.3. All-solid-state asymmetric supercapacitor. Recently, asymmetric hybrid supercapacitors were demonstrated with pseudocapacitive metal oxide/sulfide as the positive electrode and EDLC-type activated carbon as the negative electrode. The advantages of these supercapacitors are higher cell voltage with a high specific energy. A schematic of the fabricated asymmetric supercapacitor (ASC) with an alkali/PVA-based polymer gel electrolyte and its energy storage mechanism is shown in Fig. 6. During the charge-discharge process, $\mathrm{K}^{+}$and $\mathrm{OH}^{-}$ions move towards the negative and positive electrodes, respectively. In the negative electrode side, adsorption/desorption of $\mathrm{K}^{+}$ions leads to EDLC behavior, whereas at the positive electrode side, reversible fast surface redox reactions by $\mathrm{OH}^{-}$ions lead the pseudocapacitive behavior. ${ }^{31,34}$ The cell voltage of the asymmetric supercapacitor could be optimized based on the working potential range of the negative and positive electrodes in a three-electrode configuration. Fig. 7a shows the working potential range of the negative (from

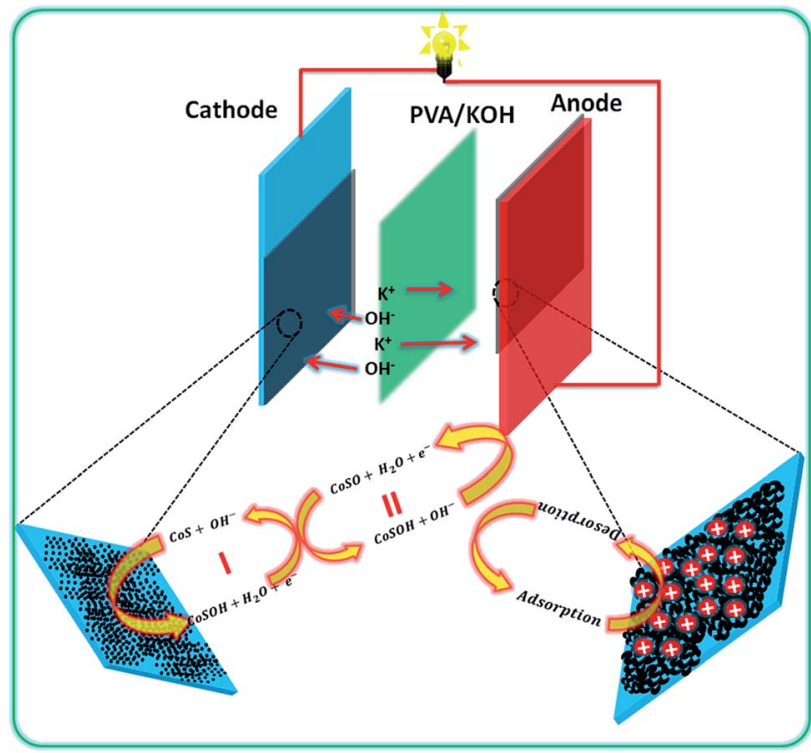

Fig. 6 Schematic of the flexible asymmetric supercapacitor fabrication with $\mathrm{PVA} / \mathrm{KOH}$-based all-solid-state electrolyte and their energy storage mechanism. 
0 to $0.6 \mathrm{~V} v s . \mathrm{Hg} / \mathrm{HgO}$ ) and positive (from -1.0 to $0 \mathrm{~V} v s$. $\mathrm{Hg} / \mathrm{HgO}$ ) electrodes at a constant scan rate. Based on the individual electrode potentials, the cell voltage of the fabricated flexible all-solidstate asymmetric supercapacitor with alkali/PVA-based polymer gel electrolyte was fixed at $1.8 \mathrm{~V}$ (Fig. 7b). To obtain better ASC performance, it is necessary to maintain the charge balance between the two electrodes using the following relationship: $q_{+}=$ $q_{-}$, where the $q_{+}$and $q_{-}$are the stored charges in the positive and negative electrode surfaces, respectively. The amount of charge stored on the electrodes depends on the capacitance $(C)$, working potential $(\Delta E)$, and mass of the electrode materials $(m)$. Thus, the mass balance equation is expressed as follows: $:^{34,46,47}$

$$
\begin{gathered}
q_{+}=C_{+} \times \Delta E_{+} \times m_{+} \\
q_{-}=C_{-} \times \Delta E_{-} \times m_{-} \\
\frac{m_{+}}{m_{-}}=\frac{C_{-} \times \Delta E_{-}}{C_{+} \times \Delta E_{+}}
\end{gathered}
$$

Based on the positive and negative electrode performance studies, the calculated optimal mass ratio of positive electrode $\left(m_{+}\right)$and negative electrode $\left(m_{-}\right)$was 0.387 for the best ASC performance.

Electrochemical performance of the fabricated flexible ASC was evaluated using $\mathrm{CV}$ profiles at different working potential ranges at a scan rate of $50 \mathrm{mV} \mathrm{s}^{-1}$. At the cell voltage of $1.8 \mathrm{~V}$, the
ASC shows significant rectangular-shaped CV profiles with redox peaks indicating the synergistic effect of pseudocapacitance and EDLCs (Fig. 7c). A maximum specific capacitance of $47 \mathrm{~F} \mathrm{~g}^{-1}$ was obtained at $1.8 \mathrm{~V}$ and the specific capacitance decreased when the cell voltage decreased. At the cell voltage of $1.2 \mathrm{~V}$, the ASC showed a specific capacitance of $29 \mathrm{~F} \mathrm{~g}^{-1}$. The CV profile of the ASC at different working cell voltages, such as 1.4, 1.6 , and $1.8 \mathrm{~V}$, with various scan rates, such as $5,25,50,75$, and $100 \mathrm{mV} \mathrm{s}^{-1}$, are shown in Fig. S3. $\dagger$ It could be clearly seen that the shape of the CV curve does not change with the increasing scan rate as well as increasing cell voltage, which indicates that there was no oxygen or hydrogen evolution occurring within the working cell voltage. All the CV curves clearly showed the surface redox peaks due to the presence of pseudocapacitive behavior. The CD profile of the ASC at different working cell voltages in the range of $1.4,1.6$ and $1.8 \mathrm{~V}$ with various current densities, such as 2, 4, 6, 8 and $10 \mathrm{~A} \mathrm{~g}^{-1}$, also showed a similar observation (Fig. S3†). The calculated specific capacitance at all cell voltages and all current densities are listed in Table S3 in ESI. $\uparrow$ The specific capacitances of the fabricated flexible ASC cell as a function of current densities and cell voltage are shown in Fig. S4. $\uparrow$ It could be clearly seen that at a high current density, $30 \%$ of the initial capacitance was retained. Moreover, at a low cell voltage of $1.4 \mathrm{~V}, 62 \%$ of the initial capacitance was retained as compared to that at high cell voltage of $1.8 \mathrm{~V}$. To find the mechanical flexibility of the fabricated ASC device, the CV profile was measured at different bending angles. Fig. 8a and
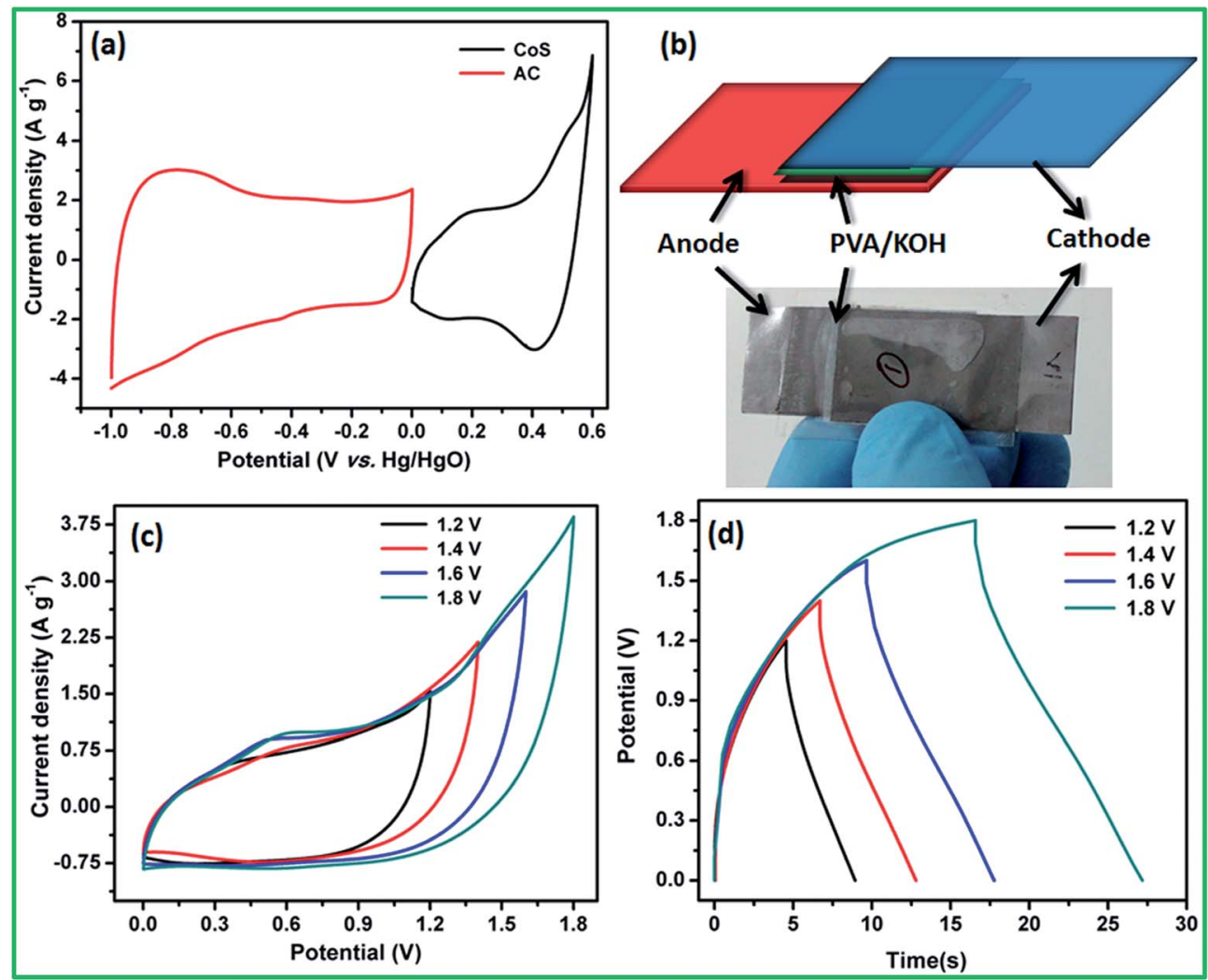

Fig. 7 (a) CV profile of the positive and negative electrodes at a scan rate of $30 \mathrm{mV} \mathrm{s}^{-1}$. (b) Image of the fabricated all-solid-state asymmetric supercapacitor device. (c) CV profile of the asymmetric cell at different cell voltages. (d) CD profile of the asymmetric cell at different cell voltages. 

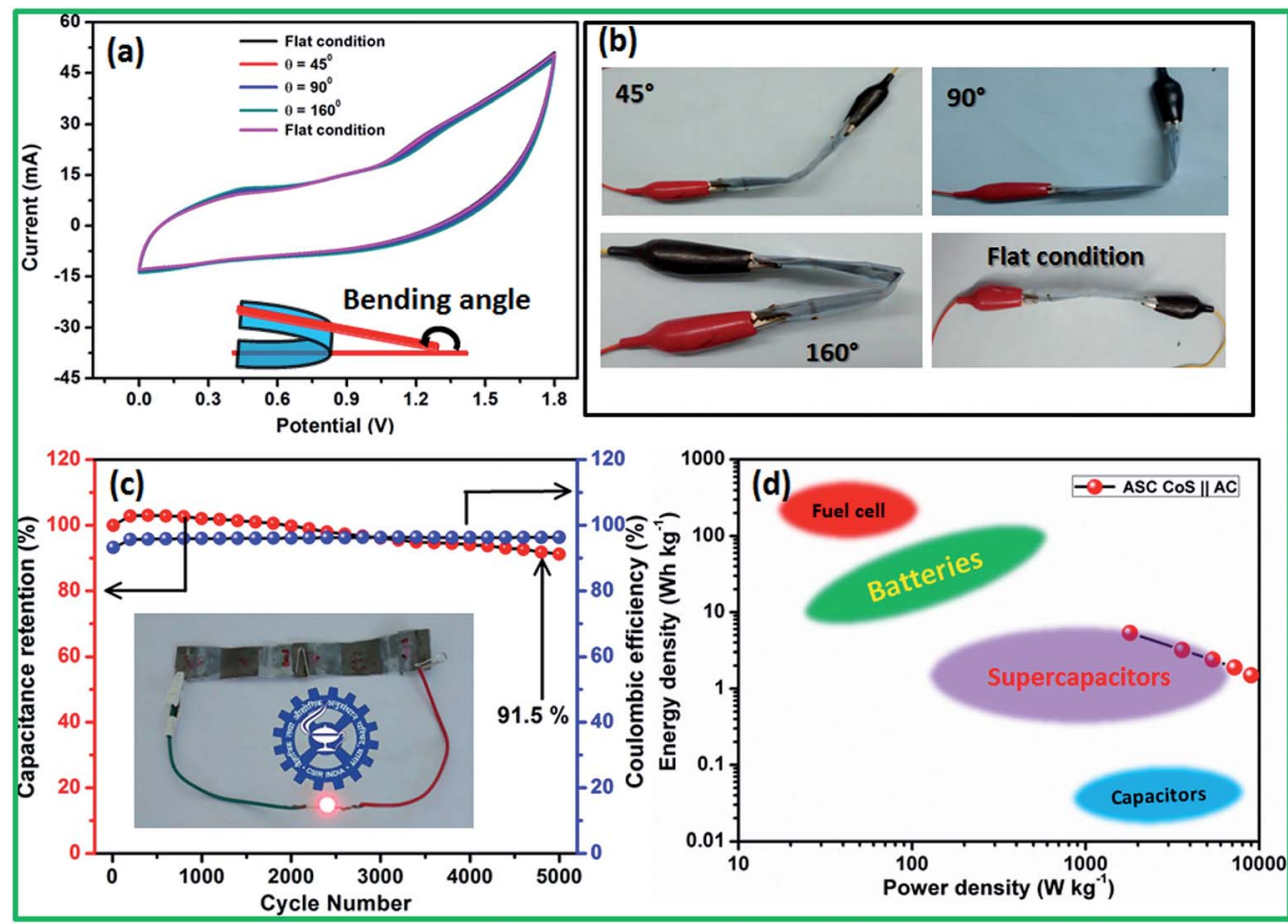

Fig. 8 (a) CV profile of the fabricated flexible ASC cell with different bending angles at a scan rate of $100 \mathrm{mV} \mathrm{s}^{-1}$. (b) Image of the bent cells. (c) Specific capacitance and coulombic efficiency of the fabricated flexible ASC cell as a function of cycle number. (d) Typical Ragone plot of the fabricated flexible ASC cell and the location, where other energy storage devices would be located on the plot, is highlighted.

b reveals the CV profiles of the fabricated flexible ASC in the maximum cell voltage of $1.8 \mathrm{~V}$ at a scan rate of $100 \mathrm{mV} \mathrm{s}^{-1}$ at different bending angles such as 45,90 , and $160^{\circ}$ (Fig. 8 a and b). Even at a higher bending angle of $160^{\circ}$, the shape and current of the CV curve was the same as that of the device at the flat position, which confirms the mechanical flexibility of the electrode materials.

For viable applications, supercapacitors should have long term electrochemical stability. Moreover, the stability of the fabricated flexible ASC was evaluated for 5000 cycles at the high current density of $10 \mathrm{~A} \mathrm{~g}^{-1}$ (Fig. 8c). The specific capacitance as a function of cycle number shows an excellent electrochemical stability of $>92 \%$ after 5000 cycles. To the best of our knowledge, this is one of the best values among those reported for flexible ASCs. For instance, Zhang et al. ${ }^{48}$ reported the CuS ||AC asymmetric cell with $88 \%$ capacitance retention after 4000 cycles and Rakhi et $a .^{34}$ reported the $\mathrm{Co}_{9} \mathrm{~S}_{8}$ nanoflakes||AC asymmetric cell with $90 \%$ of the initial capacitance even after 5000 cycles. Similarly, Wu et al. ${ }^{47}$ demonstrated the cobalt chloride carbonate hydroxide nanowire arrays (CCCH NWAs)||AC asymmetric supercapacitor with $73.7 \%$ of the initial capacitance after 2000 cycles. Dai et $a l .^{49}$ demonstrated the asymmetric supercapacitor based on $\mathrm{Ni}_{3} \mathrm{~S}_{2} /$ MWCNT-NC||AC with $90 \%$ of the capacitance retention after 5000 cycles. Singh et al. ${ }^{50}$ reported the MWCNT/ $\mathrm{NiS//GNP-based} \mathrm{asymmetric} \mathrm{supercapacitor} \mathrm{that} \mathrm{exhibited}$ a capacitance retention of $92 \%$ after 1000 cycles.

The typical Nyquist plot of the fabricated flexible ASC cell showed a $R_{\mathrm{s}}$ and $R_{\mathrm{ct}}$ value of 4.2 and $1.04 \Omega$, respectively (Fig. S5†). The straight line in the high frequency region is more vertical and has less imaginary parts, which implies that the fabricated ASC cell has a low diffusion resistance (Warburg impedance, $W$ ). $R_{\mathrm{L}}$ and $C_{\mathrm{L}}$ are denoted as leakage resistance and mass capacitance, respectively. From the EIS studies, it was confirmed that the fabricated ASC cell has excellent electrical contact with minimum ionic resistance. The coulombic efficiency of the ASC cell was maintained at $96 \%$ for all 5000 cycles at the high current density of $10 \mathrm{~A} \mathrm{~g}^{-1}$. Thus, the optimization of the fabricated flexible ASC cell voltage is essential for commercial applications. To achieve higher cell voltages, two asymmetric cells were connected in a series configuration to obtain a cell voltage of $3.6 \mathrm{~V}$. Fig. $\mathrm{S} 6 \dagger$ reveals the CD profiles of the fabricated flexible ASC in a single cell and two cells connected in series configurations at $1 \mathrm{~A} \mathrm{~g}^{-1}$ current density. The CD profile shows an ideal pseudocapacitive behavior at the cell voltage from 0 to $3.6 \mathrm{~V}$; this clearly indicates that the working cell voltage could be increased to $3.6 \mathrm{~V}$ by connecting two cells in series. Fig. S7† shows the CD profile of the fabricated flexible ASC with two cells connected in series configurations at different current densities.

The performance of a supercapacitor is rated in terms of energy density and power density. The typical Ragone plot of the fabricated flexible ASC cell at the cell voltage of $1.8 \mathrm{~V}$ clearly indicates that the fabricated device has a wide range of energy and power densities (Fig. 8d). It could be clearly seen from the plot that the fabricated ASC can provide a high energy density without sacrificing much power density. The fabricated CoS ||ACbased flexible all-sold-state ASC cell exhibited a remarkably high energy density and a power density of $5.3 \mathrm{~W} \mathrm{~h} \mathrm{~kg}^{-1}$ and $1800 \mathrm{~W}$ $\mathrm{kg}^{-1}$ at $2 \mathrm{~A} \mathrm{~g}^{-1}$ current density, respectively. Even at a high 
current density (10 $\mathrm{A} \mathrm{g}^{-1}$ ), the fabricated ASC cell delivered the energy density of $1.53 \mathrm{~W} \mathrm{~h} \mathrm{~kg}{ }^{-1}$ with a high power density of $9000 \mathrm{~W} \mathrm{~kg}^{-1}$. These values were much closer to the recently reported values for all-solid-state asymmetric supercapacitor cells (Table S2 $\dagger$ ). The remarkable electrochemical performance of the fabricated all-solid-state flexible ASC can be attributed to the good combination of ultra-fine and highly crystalline CoS nanoparticles and activated carbon electrodes. To reduce the cost of the supercapacitor for viable applications, the cells were fabricated without affecting the cell performance using polymer gel electrolyte and the cells were flexible and bendable in nature. Note that this method is facile and scalable for the bulk preparation of CoS nanoparticles for large scale commercial applications. In addition, this methodology could be readily extended to the preparation of other metal sulfides.

\section{Conclusions}

The facile synthesis of crystalline hexagonal dumb-bell-shaped CoS nanoparticles was demonstrated using solvothermal decomposition of the CoHCF complex. $\mathrm{Na}_{2} \mathrm{~S}$ and ascorbic acid acted as sulphur source and reducing agent to prevent oxide formation, respectively. The electron microscopy analysis revealed the formation of dumb-bell-shaped CoS by the selfassembly of nanocrystalline CoS particles of 10-20 nm in size. This shape of the nanoparticles enhanced the electrochemical active sites and easy permeability of electrolyte for enhanced redox reactions. Electrochemical studies showed the specific capacitance of 307 and $60 \mathrm{~F} \mathrm{~g}^{-1}$ at $5 \mathrm{~A} \mathrm{~g}^{-1}$ for $\mathrm{CoS}$ nanoparticles and the AC electrode, respectively, in the three-electrode configuration with low resistance. Moreover, the CoS nanoparticles and AC electrodes showed appropriate potential windows that could be used as negative and positive electrodes in the asymmetric supercapacitors. The fabricated flexible allsolid-state ASC cell delivered a maximum cell voltage of $1.8 \mathrm{~V}$ with high energy and power densities of $5.3 \mathrm{~W} \mathrm{~h} \mathrm{~kg}^{-1}$ and $1800 \mathrm{~W} \mathrm{~kg}^{-1}$, respectively, at the current density of $5 \mathrm{~A} \mathrm{~g}^{-1}$. In addition, the ASC cell exhibited an excellent electrochemical stability of $92 \%$ even after 5000 cycles at the current density of $10 \mathrm{~A} \mathrm{~g}^{-1}$. This solvothermal decomposition of metal hexacyanoferrate complex through the respective sulfide methodology could be readily extended for the preparation of other metal sulfides.

\section{Acknowledgements}

K. S. would like to thank DST, India for the financial support through DST-INSPIRE fellowship (IF131153) and M. S. would like to thank CSIR-INDIA for the financial support through MULTIFUN (CSC0101) project.

\section{Notes and references}

1 B. E. Conway, Electrochemical Supercapacitors Scientific Fundamentals and Technological Applications, Springer, US, Boston, MA, 1999.

2 M. Winter and R. J. Brodd, Chem. Rev., 2004, 104, 4245-4270.
3 J. R. Miller and P. Simon, Science, 2008, 321, 651-652.

4 P. Simon and Y. Gogotsi, Nat. Mater., 2008, 7, 845-854.

5 L. L. Zhang and X. S. Zhao, Chem. Soc. Rev., 2009, 38, 25202531.

6 P. Simon, Y. Gogotsi and B. Dunn, Science, 2014, 343, 12101211.

7 B. E. Conway and W. G. Pell, J. Solid State Electrochem., 2003, 7, 637-644.

8 Z. Yu, L. Tetard, L. Zhai and J. Thomas, Energy Environ. Sci., 2015, 8, 702-730.

9 G. Wang, L. Zhang and J. Zhang, Chem. Soc. Rev., 2012, 41, 797-828.

10 P. Yang and W. Mai, Nano Energy, 2014, 8, 274-290.

11 T. Lin, C. Dai and K. Hung, Sci. Rep., 2014, 4, 7274.

12 K. Subramani, D. Jeyakumar and M. Sathish, Phys. Chem. Chem. Phys., 2014, 16, 4952-4961.

13 K. Subramani, N. Lakshminarasimhan, P. Kamaraj and M. Sathish, RSC Adv., 2016, 6, 15941-15951.

14 M. Sathish, S. Mitani, T. Tomai and I. Honma, J. Mater. Chem., 2011, 21, 16216.

15 B. Amutha and M. Sathish, J. Solid State Electrochem., 2015, 19, 2311-2320.

16 X. Meng, J. Deng, J. Zhu, H. Bi, E. Kan and X. Wang, Sci. Rep., 2016, 6, 21717.

17 M. Sathish, S. Mitani, T. Tomai and I. Honma, J. Phys. Chem. $C, 2012,116,12475-12481$.

18 G.-C. Li, M. Liu, M.-K. Wu, P.-F. Liu, Z. Zhou, S.-R. Zhu, R. Liu and L. Han, RSC Adv., 2016, 6, 103517-103522.

19 E. Zhang and Y. Ni, RSC Adv., 2016, 6, 106465-106472.

20 X. Wang, H. Xia, X. Wang, B. Shi and Y. Fang, RSC Adv., 2016, 6, 97482-97490.

21 J. Xu, Y. Yang, H. Chu, J. Tang, Y. Ge, J. Shen and M. Ye, RSC Adv., 2016, 6, 100504-100510.

22 H. Chang and H. Wu, Energy Environ. Sci., 2013, 6, 3483.

23 S. Bao, C. M. Li, C. Guo and Y. Qiao, J. Power Sources, 2008, 180, 676-681.

24 H. Wan, X. Ji, J. Jiang, J. Yu, L. Miao, L. Zhang, S. Bie, H. Chen and Y. Ruan, J. Power Sources, 2013, 243, 396-402.

25 Z. Yang, C. Y. Chen and H. T. Chang, J. Power Sources, 2011, 196, 7874-7877.

26 D. P. Dubal, G. S. Gund, C. D. Lokhande and R. Holze, Energy Technol., 2014, 2, 401-408.

27 Q. Wang, L. Jiao, H. Du, J. Yang, Q. Huan, W. Peng, Y. Si, Y. Wang and H. Yuan, CrystEngComm, 2011, 13, 6960.

28 M. Sathish, S. Mitani, T. Tomai and I. Honma, J. Mater. Chem. A, 2014, 2, 4731.

29 D. Jiang, Z. Jin, D. Henderson and J. Wu, J. Phys. Chem. Lett., 2012, 3, 1727-1731.

30 H. Yu, J. Wu, L. Fan, S. Hao, J. Lin and M. Huang, J. Power Sources, 2014, 248, 1123-1126.

31 J. Chen, J. Xu, S. Zhou, N. Zhao and C. Wong, Nano Energy, 2016, 21, 145-153.

32 R. Wang and X. Yan, Sci. Rep., 2014, 4, 3712.

33 Z. A. Yu, C. Li, D. Abbitt and J. Thomas, J. Mater. Chem. A, 2014, 2, 10923-10929.

34 R. B. Rakhi, N. A. Alhebshi, D. H. Anjum and H. N. Alshareef, J. Mater. Chem. A, 2014, 2, 16190-16198. 
35 S. Liu, C. Mao, Y. Niu, F. Yi, J. Hou, S. Lu, J. Jiang, M. Xu and C. Li, ACS Appl. Mater. Interfaces, 2015, 7, 25568-25573.

36 J. Shi, X. Li, G. He, L. Zhang and M. Li, J. Mater. Chem. A, 2015, 3, 20619-20626.

37 C.-C. Yang, S.-T. Hsu and W.-C. Chien, J. Power Sources, 2005, 152, 303-310.

38 F. F. Hatta, M. Z. A. Yahya, A. M. M. Ali, R. H. Y. Subban, M. K. Harun and A. A. Mohamad, Ionics, 2005, 11, 418-422.

39 K. Subramani, S. Kowsik and M. Sathish, ChemistrySelect, 2016, 1, 3455-3467.

40 B. D. Cullity and S. R. Stock, Elements of X-Ray Diffraction, Addison-Wesley, 1956.

41 M. Berrettoni, M. Giorgetti, S. Zamponi, P. Conti, D. Ranganathan, A. Zanotto, M. L. Saladino and E. Caponetti, J. Phys. Chem. C, 2010, 114, 6401-6407.

42 O. Sato, T. Iyoda, A. Fujishima and K. Hashimoto, Science, 1996, 272, 704-705.
43 P. Zanello, Inorganic Electrochemistry, Royal Society of Chemistry, Cambridge, 2003.

44 F. Wang, S. Xiao, Y. Hou, C. Hu, L. Liu and Y. Wu, RSC Adv., 2013, 3, 13059.

45 R. R. Salunkhe, J. Tang, Y. Kamachi, T. Nakato, J. H. Kim and Y. Yamauchi, ACS Nano, 2015, 9, 6288-6296.

46 W. Liu, X. Li, M. Zhu and X. He, J. Power Sources, 2015, 282, 179-186.

47 D. Wu, T. Xiao, X. Tan, P. Xiang, L. Jiang, Z. Kang and P. Tan, Electrochim. Acta, 2016, 198, 1-9.

48 J. Zhang, H. Feng, J. Yang, Q. Qin, H. Fan, C. Wei and W. Zheng, ACS Appl. Mater. Interfaces, 2015, 7, 21735-21744.

49 C.-S. Dai, P.-Y. Chien, J.-Y. Lin, S.-W. Chou, W.-K. Wu, P.-H. Li, K.-Y. Wu and T.-W. Lin, ACS Appl. Mater. Interfaces, 2013, 5, 12168-12174.

50 A. Singh, A. J. Roberts, R. C. T. Slade and A. Chandra, J. Mater. Chem. A, 2014, 2, 16723-16730. 